Chapter 6

\title{
Naringenin Inhibits Oxidative Stress Induced \\ Macromolecular Damage in N-methyl N-nitro \\ N-nitrosoguanidine Induced Gastric \\ Carcinogenesis in Wistar Rats
}

\author{
Ekambaram Ganapathy, Devaraja Rajasekaran, \\ Murugan Sivalingam, Muhammed Farooq Shukkur, \\ Ebrahim Abdul Shukkur and \\ Sakthisekaran Dhanapal
}

Additional information is available at the end of the chapter

http://dx.doi.org/10.5772/45896

\section{Introduction}

Neoplasia of the stomach represents the second most recurrent cause of cancer mortality in the world [1]. Despite major efforts, the number of deaths from gastric cancer has not decreased in recent years. There have also been major efforts to better understand the mechanisms responsible for oncogenesis and a number of animal models of have been developed to study the correlates of gastric carcinoma in recent years [2, 3]. Among these, the 1-methyl-3-nitro-1-nitrosoguanidine (MNNG) model has proven to be very useful. Evidences suggest that MNNG administration results in oncogenesis as a result of increased free radical synthesis in the gastric mucosa [4,5]. DNA damage induced by oxidative stress and/or deficient DNA-repair is reported to have an etiological or prognostic role in cancer [4].

Research also suggests that electrophiles could play a key role in chemical carcinogenesis. The oxidative inactivation of enzymes by free radicals and accumulation of oxidized proteins may play a critical role in the alteration of cellular function and cell death. Oxidative damage can generate large amounts of carbonyl products and hence measurement of these components could reflect oxidative protein damage [6]. Synthesis of certain polyamines notably histamine, putrescine, spermine and spermidine is essential for the regulation of protein, RNA and DNA synthesis. In addition, the ability of polyamines to alter DNA-protein 
interactions could disrupt certain cellular functions under cancerous conditions [7]. These biomarkers are biological and molecular end-points that are quantitatively modulated by chemopreventive agents and as such could indicate the efficacy of the dietary agents.

Dietary antioxidants are important health-protecting factor. Studies have convincingly stated that frequent consumption of fruits and vegetables rich in antioxidants could decrease the risk of cancer [8]. Naringenin, a flavanone compound highly enriched in grapefruits, has been identified as a possible inhibitor of cell proliferation and potential to act as an antitumorigenic agent [9-11]. We recently reported that naringenin could reduce tumor size, ROS levels and enhance antioxidant status [12]. However, the mechanism of action of naringenin to suppress cell growth is still ambiguous since this compound appears to have multiple cellular targets including cytochrome P450 enzymes [13]. We analyzed gastric cancer induced by MNNG, which reportedly induce cellular oxidative damage through DNA strand breaks [14] and explored the possible protective role of naringenin by measuring the levels of protein damage and polyamine synthesis in MNNG-induced gastric carcinogenesis in experimental rats.

\section{Materials and methods}

\subsection{Drugs and chemicals}

MNNG, Naringenin [ 95\%, $\mathrm{C}_{15} \mathrm{H}_{12} \mathrm{O}_{5} ;( \pm)$-2,3-Dihydro-5,7-dihydroxy-2-(4-hydroxy phenyl) -4H-1-benzopyran-4-one 4',5,7-Trihydroxyflavanone, Molecular Weight: 272.25, CAS Number 67604-48-2] Histopaque 1077, RPMI 1640 and BSA were purchased from Sigma (St.Louis, MO, USA), Hanks Balanced Salt Solution from Himedia (Mumbai, India), LMPA and other chemicals of analytical grade were purchased from SRL, Mumbai, India.

\subsection{Animals}

All the experiments were carried out with male Wistar rats 6-8 weeks old (80-90g) obtained from the Central Animal House, University of Madras, Dr. ALM PG IBMS, Taramani, Chennai, Tamilnadu, India. The rats were housed six in a polypropylene cage and provided food and water ad libitum. The animals were maintained under standard conditions of temperature $\left(23 \pm 2^{\circ} \mathrm{C}\right)$ and humidity $(50-70 \%)$ with an alternating 12-hour light/dark cycle with free access to standard pellet diet (Mysore Snack Feed Ltd, Mysore, India) and maintained in accordance with the guidelines of the National Institute of Nutrition, Indian Council of Medical Research (ICMR), Hyderabad, India and approved by the ethical committee of University of Madras (IAEC no. 02/055/05).

\subsection{Treatment schedule}

Rats in Group I served as control and was given oral corn oil for 20 weeks. Group II animals were induced with MNNG $200 \mathrm{mg} / \mathrm{kg}$ b. wt, by oral gavage at days 0 and 14 and saturated $\mathrm{NaCl}(1 \mathrm{ml} / \mathrm{rat})$ was given 3 days once for four weeks and maintained till the end of the ex- 
perimental period. Group III animals were induced with $\mathrm{MNNG}+\mathrm{NaCl}$ (as in group II) and treated with naringenin ( $200 \mathrm{mg} / \mathrm{kg}$ b.wt, dissolved in corn oil, orally) simultaneously for 20 weeks from the first dose of MNNG $+\mathrm{NaCl}$. Group IV animals were post-treated with naringenin $\left(200 \mathrm{mg} / \mathrm{kg}\right.$ b.wt, dissolved in corn oil, orally) from the $6^{\text {th }}$ week of MNNG (as in group II) induction up to end of experimental period. Group V animals were treated with naringenin ( $200 \mathrm{mg} / \mathrm{kg}$ b.wt, dissolved in corn oil, orally) alone for 20 weeks. The experiment was terminated at the end of 20 weeks and all the animals were sacrificed by cervical dislocation after an overnight fasting.

\subsection{Tumour weight}

Tumour weight was estimated according to the method of Geren et al.,[15]. The resultant solid tumour was considered to be prelate ellipsoid with one long axis and two short axes. The two short axes were measured using a vernier caliper. The tumour weight was calculated by multiplying the length of the tumour with the square of the width and dividing the product by 2 .

\subsection{Analysis of ROS}

To examine the in vivo generation of ROS, we used the cell permeable probe 2', 7'-dichlorodihydrofluorescin diacetate (CM- $\mathrm{H}_{2} \mathrm{DCFH}-\mathrm{DA}$; Molecular Probes, Eugene, OR, USA) according to the method described by Parsons et al.,[16]

\subsection{Biochemical analysis}

The oxidative protein damage was determined by the estimation of carbonyl content by the method of Levins et al., [17]. Protein content was estimated by the method of Lowry et al., [18]. The DNA and RNA contents were estimated in the homogenate by the method of Burton [19] and Rawal et al., [20]. Lipid peroxidation (LPO) was estimated by the method of Ohkawa et al., [21].

\subsection{DNA fragementation}

The extent of DNA fragmentation was measured by the method of Sellins and Cohen [22]. The isolated DNA was visualized for fragmentation by electrophoresis in a $1.2 \%$ agarose gel containing ethidium bromide.

\subsection{Assessment of DNA damage}

DNA damage was assessed with alkaline single cell gel electrophoresis (comet assay) according to the method described by Singh et al., [23].

\subsection{Polyamine analysis}

Separation of various polyamine fractions such as histamine, putrescine, spermine and spermidine and their subsequent estimation was done by the method of Endo [24]. CM-cellulose 
column chromatography: Rat tissues (stomach-100 mg) were homogenized in ice-cold $0.4 \mathrm{M}$ $\mathrm{HClO}_{4}$ containing $2 \mathrm{mM}$ ethylenediaminetetracetic acid. The homogenate was centrifuged at $1000 \mathrm{~g}$ for $5 \mathrm{~min}$. The neutralized supernatant was applied to a CM cellulose column. Each sample solution $(0.5-3 \mathrm{~mL})$ was applied to a CM-cellulose column $(0.6 \times 10 \mathrm{~cm})$ equilibrated with $0.01 \mathrm{M}$ phosphate buffer ( $\mathrm{pH}$ 6.2). After the column was washed with $15 \mathrm{~mL}$ of $0.01 \mathrm{M}$ phosphate buffer ( $\mathrm{pH}$ 6.2) and $15 \mathrm{~mL}$ of $0.03 \mathrm{M}$ phosphate buffer ( $\mathrm{pH}$ 6.2), histamine, putrescine, spermidine and spermine were eluted out from the column with borate buffer without $\mathrm{NaCl}(30 \mathrm{~mL})$, borate buffer containing $0.03 \mathrm{M} \mathrm{NaCl}(20 \mathrm{~mL})$, borate buffer containing 0.075 $\mathrm{M} \mathrm{NaCl}(20 \mathrm{~mL})$, and borate buffer containing $0.15 \mathrm{M} \mathrm{NaCl}(20 \mathrm{~mL})$, respectively. Fractions (3 mL) were collected at a flow rate of approximately $3 \mathrm{~mL} / \mathrm{min}$. Trinitrobenzenesulphonate (TNBS) reagent $(1 \mathrm{~mL})$ was added to the elute $(3 \mathrm{~mL})$ from the $\mathrm{CM}$-cellulose column. The reaction was carried out at $50^{\circ} \mathrm{C}$ for $10 \mathrm{~min}$ and terminated by cooling the reaction mixture in water. Absorbance at $420 \mathrm{~nm}$ was measured within $20 \mathrm{~min}$.

\subsection{Statistical analysis}

The data are presented as mean \pm SD for six rats in each group. Significance of the differences between mean values was determined by one-way analysis of variance (ANOVA) followed by the Duncan test for multiple comparison. P values 0.001, 0.01, 0.05 were considered to reveal significance.

\section{Results}

The mean body weights were decreased and tumor weights increased in group II (MNNG + $\mathrm{S}-\mathrm{NaCl}$ ) animals as compared with all the other groups (Table 1). A 100\% incidence in gastric cancer was noticed among group II animals. Importantly, naringenin treatment significantly increased the body weight and decreased the tumor weights among group III $(p<0.05)$ and IV animals as compared to group II animals. Furthermore, a progressive increase in the mean body weight was observed among group $\mathrm{V}$ animals during the experimental period. Conceptually, the increase in body weight after the administration of naringenin in Group III and Group IV rats highlights the protective efficacy of the flavonoid.

A significant increase in ROS generation was observed in stomach and liver tissue of MNNG induced groups II animals as compared with control animal group I (Fig. 1). However, there was significantly decreased activity in group III and group IV naringenin treated animals. The results were suggested that the antioxidant effect of naringenin in MNNG induced animals could be due to its free radical scavenging action.

Figure $2 \mathrm{a}$ and $2 \mathrm{~b}$ shows the levels of LPO and protein carbonyl content in stomach and liver tissues of various experimental groups. A significant $(p<0.001)$ increase in the extent of LPO and protein carbonyl content was observed in the stomach and liver of carcinoma bearing group II animals as compared to the control animals (group I). Naringenin significantly decreased the LPO and protein carbonyls of group III and group IV animals $(p<0.001, p<0.01)$ as compared to carcinogen-induced group II rats. However, naringenin alone treated ani- 
mals (group V) did not show any significant change as compared with the control animals (group I).

\begin{tabular}{llllll}
\hline Groups & Group I (Control) & $\begin{array}{c}\text { Group II (MNNG + (Naringenin } \\
\text { NaCl Induced) } \\
\text { simultaneous } \\
\text { treatment) }\end{array}$ & $\begin{array}{l}\text { Group IV } \\
\text { (Naringenin post (Naringenin } \\
\text { treatment) }\end{array}$ & $\begin{array}{l}\text { Group V } \\
\text { alone) }\end{array}$ \\
\hline Body Weight (g) & $310.17 \pm 15.78$ & $166.41 \pm 16.80 \mathrm{a}^{\#}$ & $270.18 \pm 17.99 \mathrm{~b}^{@}$ & $\begin{array}{l}230.75 \pm \\
15.18 \mathrm{~b}^{@} \mathrm{C}^{@}\end{array}$ & $330.23 \pm 16.08$ \\
\hline Tumor weight $(\mathrm{g})$ & - & $0.72 \pm 0.05$ & $0.31 \pm 0.03 \mathrm{a}^{\#}$ & $0.51 \pm 0.04 \mathrm{a}^{@} \mathrm{~b}^{\#}$ & - \\
\hline $\begin{array}{l}\text { No. of rats with } \\
\text { gastric cancer }(\%)\end{array}$ & $0(0 \%)$ & $6 / 6(100 \%)$ & $0 / 6(0 \%)$ & $2(33.3 \%)$ & $0(\%)$ \\
\hline
\end{tabular}

Values are expressed as mean \pm SD $(n=6)$ for each group. Different letters represent significant variations as calculated by 1-way analysis of variance and the Duncan test. Body weight: $a$, as compared with group I; b, as compared with group II; c, as compared with group III. Tumor weight: a, as compared with group II. ${ }^{\circledR}-p<0.05 ;{ }^{\#}-p<0.01 ;^{*}-p<0.001$.

Table 1. Effect of naringenin on body and tumor weight and incidence of gastric cancer of control and experimental rats.

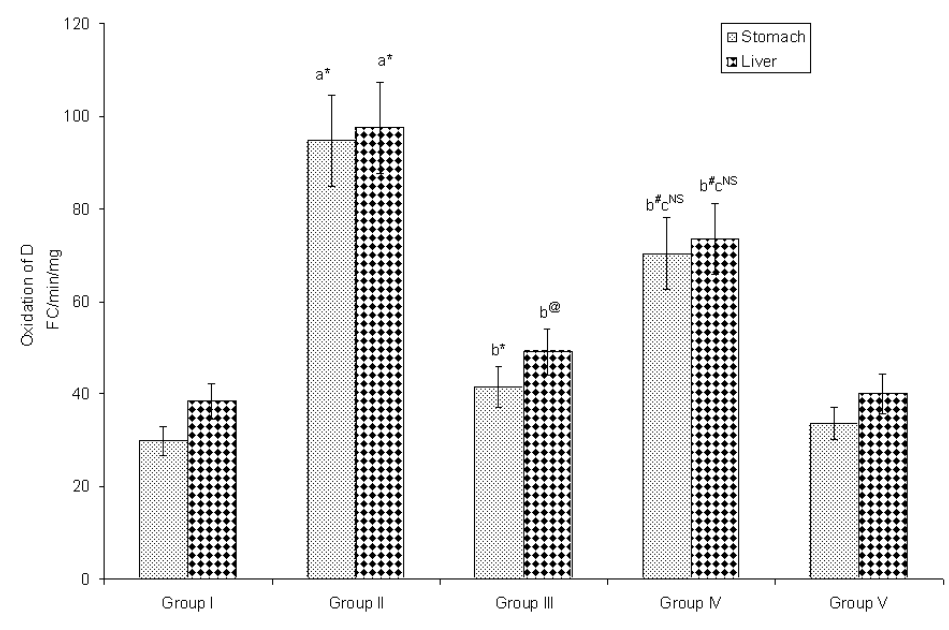

Figure 1. Effect of naringenin on ROS generation in control and experimental animals. ROS production estimated by oxidation of the fluorescent probe, DCFDA. Groups (I-V) are Control, MNNG induced, naringenin simultaneous treatment, naringenin post treated and naringenin alone respectively. The details are described under materials and methods. Values are the mean \pm SD of six rats in each group. (a-c) represent (a) as compared with Group l; (b) as compared with Group II; (c) as compared with group III ( $\left.{ }^{*} p<0.001,{ }^{\circledR} p<0.01,{ }^{*} p<0.05\right)$. 

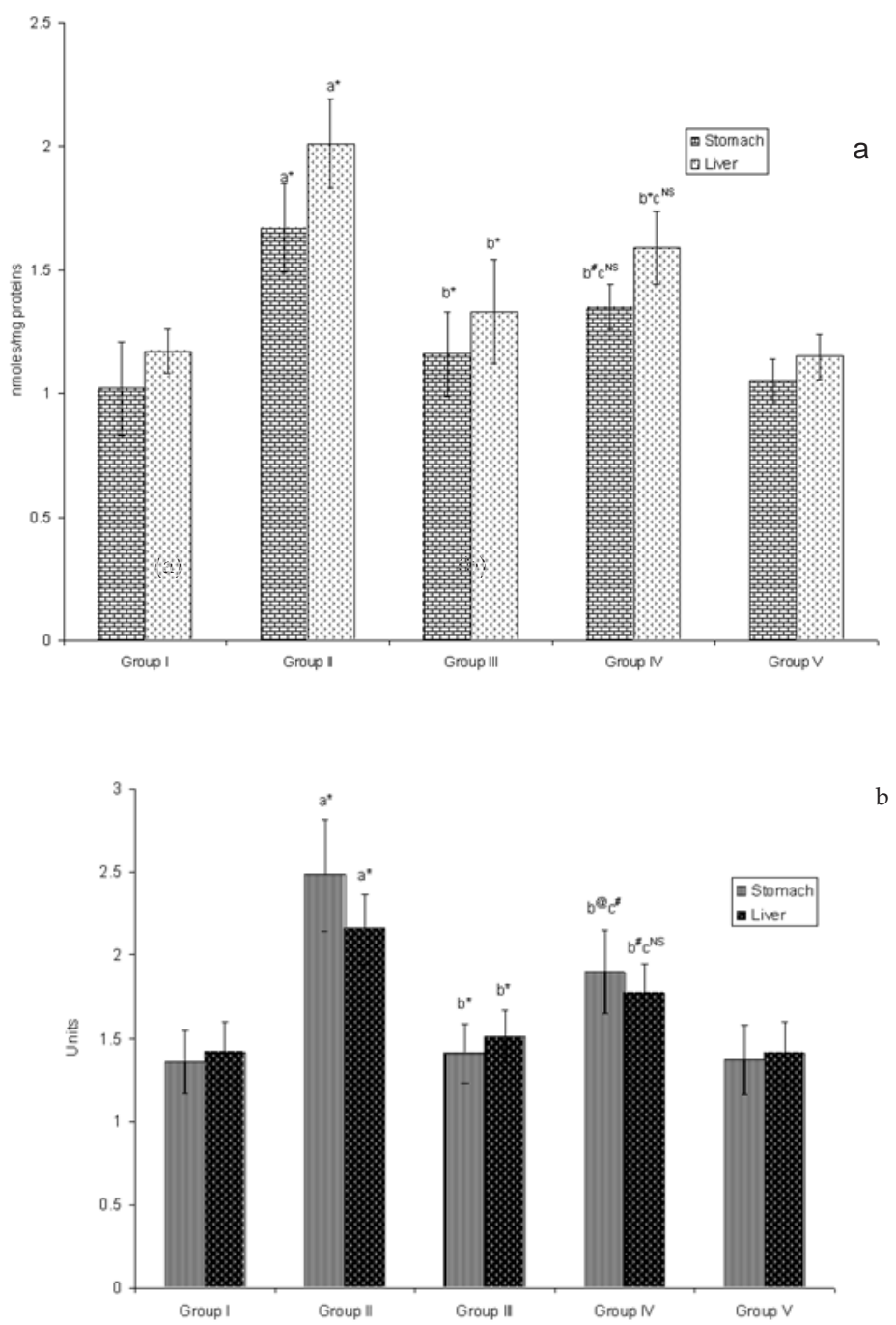

Figure 2. a. Effect of naringenin on lipidperoxidation in stomach and liver of control and experimental animals. Formation of lipid peroxidation product was determined in terms of MDA as described under materials and methods. Groups (I-V) are Control, MNNG induced, naringenin simultaneous treatment, naringenin post treated and naringenin alone respectively. Units: nmoles of MDA release/mg protein. Values are the mean \pm SD of six rats in each group. (a-c) represent (a) as compared with Group I; (b) as compared with Group II; (c) as compared with group III $\left({ }^{*} p<0.001, @ p<0.01,{ }^{*} p<0.05\right)$. b. Effect of naringenin on protein carbonyl formation in control and experimental animals. Oxidation of Stomach and liver proteins of all animals were determined in terms of protein carbonyl formation. Groups (I-V) are Control, MNNG induced, naringenin simultaneous treatment, naringenin post treated and naringenin alone respectively. The details are described under materials and methods. Units: nmoles/mg protein. Values are the mean \pm SD of six rats in each group. (a-c) represent (a) as compared with Group I; (b) as compared with Group II; (c) as compared with group III ( ${ }^{*} p<0.001,{ }^{\circledR} p<0.01$, $\left.{ }^{*} p<0.05\right)$. 
Fig. 3 shows the agarose gel electrophoretic pattern of DNA isolated from the stomach tissue of control and experimental animals. In group I control and group II cancer bearing animals, there was no significant DNA fragmentation. Naringenin treated (group III) animals exhibited a significant DNA fragmentation. In group IV animals was shown less DNA fragmentation when compared with group III. However, a significant fragmentation of DNA was observed in animals treated with naringenin alone (group V).

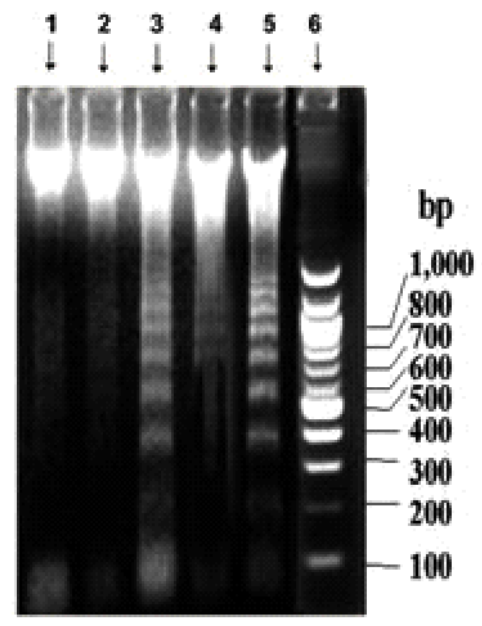

Figure 3. Effect of naringenin on DNA fragmentation in control and experimental animals. Groups (I-VI) are Control, MNNG induced, naringenin simultaneous treatment, naringenin post treated, naringenin alone and DNA marker respectively. The details are described under materials and methods. DNA was isolated by agarose gel electrophoresis and visualized by ethidium bromide staining.

Fig. 4 shows the level of DNA damage measured using single cell gel electrophoresis in stomach tissue of control and experimental animals. There was a significant increase in DNA tail length (3.21- fold) in cancer bearing animals (group II) as compared with group I control animals and significant decrease (2.27 - fold) in Group III and Group IV in (1.84-fold) (naringenin treated) animals when compared with group II animals. In addition, there was no comparable difference between rats treated with naringenin alone (group V) and the control animals.

Figure 5 and 6 shows the levels of nucleic acids and polyamines in the stomach of control and experimental animals. Cancer induced animals (group II) showed a significant increase $(\mathrm{p}<0.001)$ in nucleic acid and polyamine contents in stomach tissue when compared with the control animals (group I). On treatment with naringenin (group III and group IV), there was found to be a significant $(\mathrm{p}<0.001, \mathrm{p}<0.01)$ decrease in the levels of nucleic acids and polyamines in stomach tissue when compared with cancer-induced animals (group II). However, naringenin alone treated animals (group V) did not show any significant changes when compared with control animals (group I). 


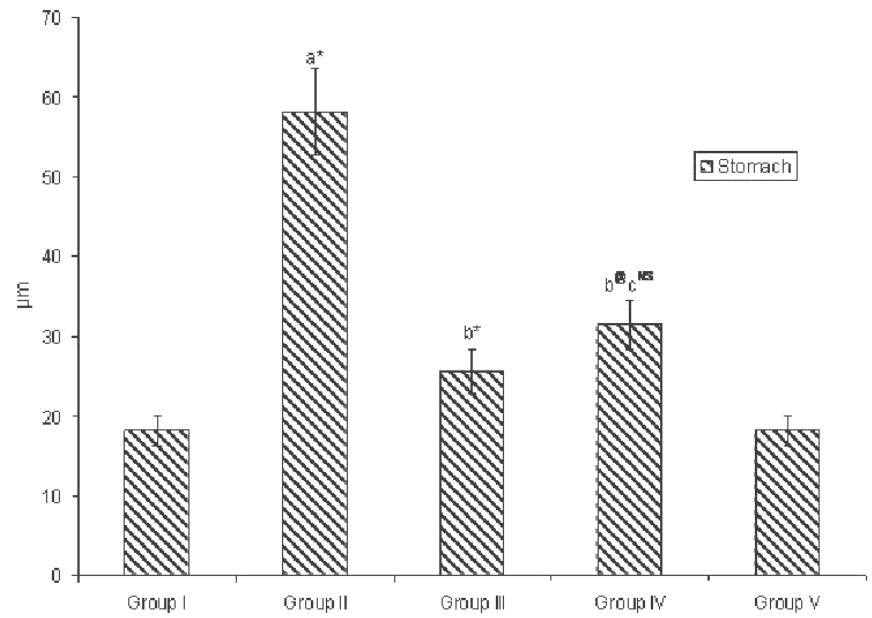

Figure 4. Effect of naringenin on DNA single strand breaks in control experimental animals. Oxidative DNA damage in stomach of control and experimental animals were determined by comet assay. Groups (I-V) are Control, MNNG induced, naringenin simultaneous treatment, naringenin post treated and naringenin alone respectively. The details are described under materials and methods. DNA tail length was expressed in $\mu \mathrm{m}$. Values are the mean \pm SD of six rats in each group. (a-c) represent (a) as compared with Group I; (b) as compared with Group II; (c) as compared with group III ( $\left.{ }^{*} p<0.001,{ }^{\circledR} p<0.01,{ }^{*} p<0.05\right)$.

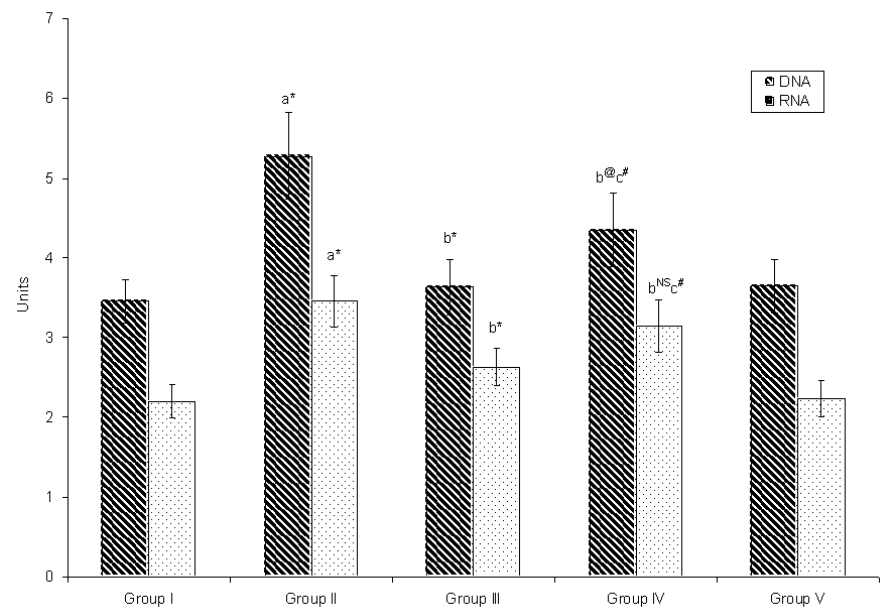

Figure 5. Effect of naringenin on the levels of nucleic acid content in stomach of control and experimental animals. Groups (I-V) are Control, MNNG induced, naringenin simultaneous treatment, naringenin post treated and naringenin alone respectively. The details are described under materials and methods. Units: $\mathrm{mg} / \mathrm{g}$ wet tissue. Values are the mean \pm SD of six rats in each group. (a-c) represent (a) as compared with Group I; (b) as compared with Group II; (c) as compared with group III ( $\left.{ }^{*} p<0.001,{ }^{\circledR} p<0.01,{ }^{*} p<0.05\right)$. 

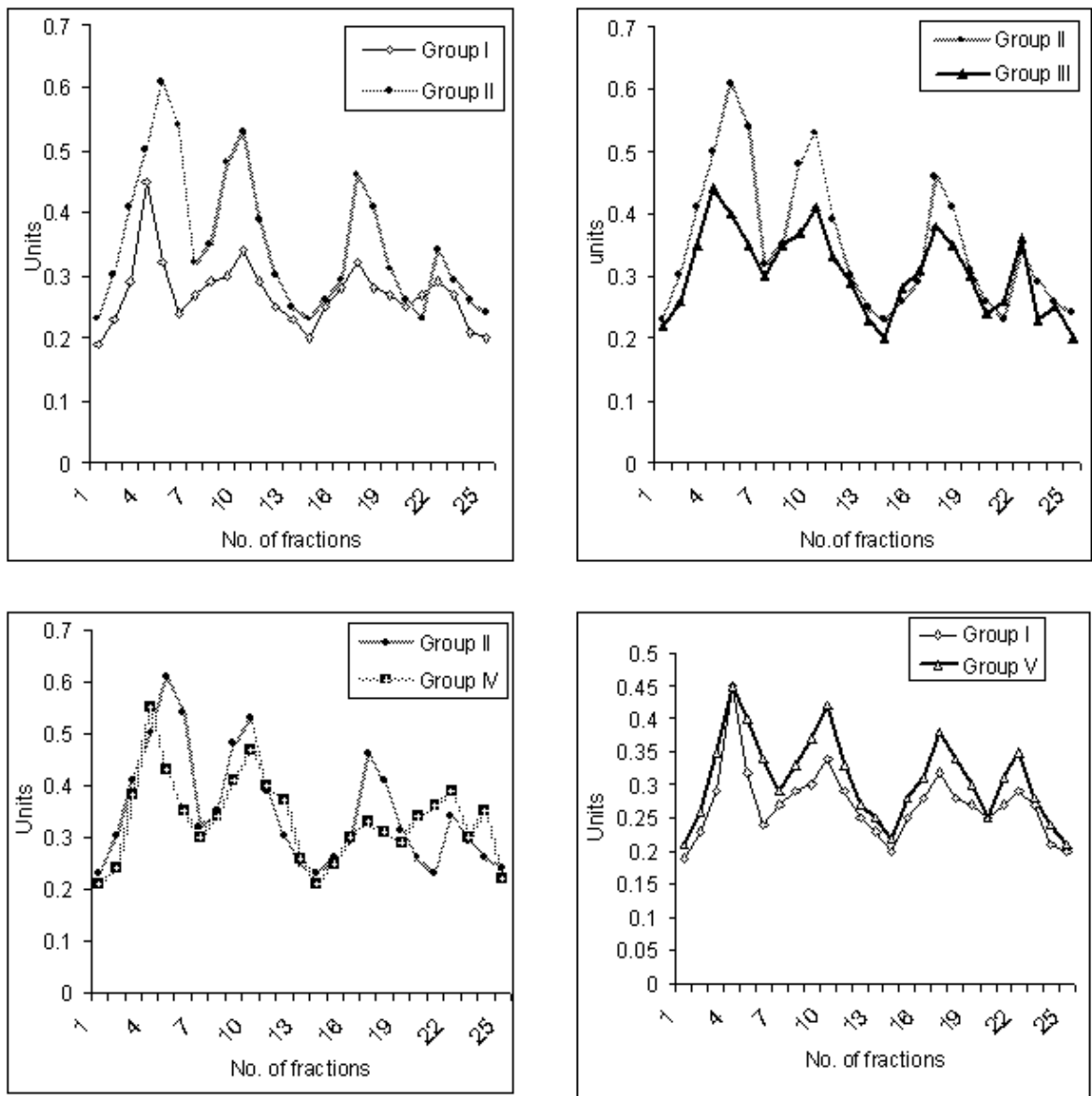

Figure 6. Effect of naringenin on the levels of polyamines in stomach of control and experimental animals. 25 fractions were collected from each group. Groups (I-V) are Control, MNNG induced, naringenin simultaneous treatment, naringenin post treated and naringenin alone respectively. The details are described under materials and methods.

\section{Discussion}

Development of a diet that provides adequate nutrition and effective cancer prevention is an important goal in nutrition and cancer research [8]. We suggest that naringenin could be an 
effective chemopreventive agent in MNNG induced gastric carcinoma. ROS and organic free radical intermediates formed from carcinogens reportedly initiate carcinogenic transformation [25]. Consequently, the accumulation of free radical mediated damage may be a possible mechanism of cancer development [26]. MNNG is an effective carcinogen with a capability to induce enormous amounts of free radicals, which in turn reacts with lipids causing release of lipid peroxides [27]. Naringenin significantly reduced the lipid peroxides and increased free radicals scavenging capabilities in cancer bearing animals, which could be due to its capability to enhance antioxidant enzymes $[28,29]$. This has been supported by our recent report that administration of naringenin to gastric carcinoma-induced rats largely upregulated the redox status to decrease the risk of cancer [12]. The antioxidant enzymes may reduce the carcinogen-DNA interaction by providing a large nucleophilic pool for the electrophilic carcinogens such as MNNG [30], and it causes oxidative protein damage in gastric carcinogenesis-induced animals [31]. Among the various oxidative modifications in protein, carbonyl formation may be an early marker for protein oxidation [32]. Protein carbonyls have been used as a biomarker of oxidative stress because of the relative stability of carbonylated proteins and the high protein concentration in blood. However, we found that tissue carbonyl levels in naringenin treated groups were decreased when compared with MNNG induced with cancer.

A number of flavonoids have been shown to suppress carcinogenesis in various animal models [33]. There is currently considerable interest in these compounds as they appear to exert a beneficial effect on several key mechanisms involved in the pathogenesis of cancer. DNA fragmentation is generally considered to be the hallmark of apoptosis. Indeed the nuclear DNA of apoptotic cells shows a characteristic laddering pattern of oligonucleosomal fragments. Several studies have demonstrated a positive correlation between DNA fragmentation and apoptosis. Medicinal plants and natural dietary constituents such as naringenin have been reported to induce apoptosis in malignant cells in vitro [34]. Our present study we observed DNA fragmentation induced by naringenin, which possess, prevention of MNNG.

Additionally, we have also observed an induction of apoptosis on naringenin in stomach cancer bearing animals as revealed by the enhancement of LPO and oxidative DNA damage. The absence of intranucleosomal DNA-fragmentation in MNNG induced animals reflects the prevention of apoptotic mechanisms in malignant cells. Our report has shown that intranucleosomal DNA fragmentation during chemoprevention of naringenin treated rats. The results support that the findings of key changes in cell death can occur without DNA fragmentation and it alone should not be considered as a criterion for assessing apoptotic cell death [35].

Feng et al., [36] reported natural antioxidants are capable of inhibiting the ROS production and thereby reducing the associated intra-cellular oxidative stress. Importantly, ROS, damaging almost all classes of subcellular components, are produced in numerous pathophysiological states and have been recognized as participating in the development of multistage carcinogenesis [37]. Oxidative stress is associated with damage to a wide range of macromolecular species including lipids, proteins, and nucleic acids thereby producing major interrelated derangements of cellular metabolism including peroxidation of lipids, 
formation of protein carbonyls, and single strand breaks in DNA [38]. Previous report from our laboratory, dietary agent could effectively inhibited B(a)P induced lung carcinogenesis by offering protection from protein damage and also by suppressing cell proliferation [39]. Our result demonstrated that naringenin; MNNG induced intracellular ROS and oxidized protein carbonyl accumulation dependent on the hydroxyl group presents in the structure $[40,41]$.

LPO is the most studied biologically relevant free radical chain reaction. It is regarded as one of the basic mechanisms of tissue damage caused by free radicals [42]. Increased level of LPO was reported during DEN induced and Phenobarbital promoted hepatocellular carcinogenesis [26]. In this result, an increased level of tail length was observed in carcinogen induced rats (Group II). The $\mathrm{OH}$ - radical is implicated to the oxidation of DNA bases, the most studied, product being 8-oxo-7, 8-dihydroguanine. Oxygen radicals attack DNA bases and deoxyribose residues producing damaged bases and single stand breaks. This radical induced oxidative stress generated a large number of modifications in DNA including strand breaks [36]. Contrary to this, the diets rich in fruits and vegetables can decrease both DNA damage and cancer incidence [43].

Polyamines are essential for the growth of cells and rapidly proliferating cells have higher levels of polyamines than do slowly growing or quiescent cells [44]. Earlier studies with different carcinoma tissues have demonstrated a marked increase in the levels of polyamines and ornithine decarboxylase (ODC) activity, confirming their correlation with neoplastic growth and high rate of cell proliferation [45]. Others cited the importance of polyamines in chemotherapy by demonstrating depleted levels of polyamines upon treatment with anticancer agents [39,46]. Earlier reports demonstrate the potential of flavonoids and alkaloids to inhibit ODC in various cancer conditions [47]. Hence, naringenin, one of the flavonoids, may inhibit ODC activity and reduce cell proliferation in stomach carcinogenesis through depleting the levels of polyamines.

One or more independent/interdependent pathways such as the inhibition of activation of MNNG to the ultimate carcinogen, it's antioxidative and free radical scavenging properties may be responsible for the anticancer potential of naringenin [48]. Our study strongly displays the protective effect of naringenin against MNNG induced gastric carcinogenesis, which may be due to its inhibitory effect on cell proliferation. Therefore, naringenin may be explored as a chemopreventive agent for humans at high risk of gastric cancer.

\section{Acknowledgments}

Ganapathy. Ekambaram gratefully acknowledges the Indian Council of Medical Research (ICMR), Ministry of Human Resources and Manpower Development, Government of India, New Delhi, India for the financial assistance awarded in the form of a senior research fellowship (Grant No: 3/2/2/96/2006/NCD-III; dt 20/9/06). 


\section{Author details}

Ekambaram Ganapathy ${ }^{1}$, Devaraja Rajasekaran², Murugan Sivalingam²,

Muhammed Farooq Shukkur ${ }^{3}$, Ebrahim Abdul Shukkur ${ }^{4}$ and Sakthisekaran Dhanapal ${ }^{2 *}$

*Address all correspondence to: g_ekambaram@yahoo.co.in

1 Department of Pathology and Lab Medicine, David Geffen School of Medicine, University of California, Los Angeles, California, USA

2 Department of Medical Biochemistry, Dr. ALM PG Institute of Basic Medical Sciences, University of Madras, Taramani Campus, Chenna, India

3 Internal Medicine, Wayne State University, School of Medicine, Detroit, Michigan, USA

4 Pharmacy Practice, Wayne State University, Detroit, Michigan, USA

\section{References}

[1] Chen, J., Rocken, C., Malfertheiner, P. and Ebert, M.P. (2004) Recent advances in molecular diagnosis and therapy of gastric cancer. Dig. Dis, 22, $380-5$.

[2] Su, Y.P., Tang, J.M., Tang, Y. and Gao, H.Y. (2005) Histological and ultrastructural changes induced by selenium in early experimental gastric carcinogenesis. World $J$ Gastroenterol, 11, 4457-60.

[3] Kodama, M., Murakami, K., Sato, R., Okimoto, T., Nishizono, A. and Fujioka, T. (2005) Helicobacter pylori-infected animal models are extremely suitable for the investigation of gastric carcinogenesis. World J Gastroenterol, 11: 7063-71.

[4] Lin, C.T., Lin, W.H., Lee, K.D. and Tzeng, P.Y. (2006) DNA mismatch repair as an effector for promoting phorbol ester-induced apoptotic DNA damage and cell killing: implications in tumor promotion. Int. J. Cancer, 119, 1776-84.

[5] Fiaschi, A.I., Cozzolino, A., Ruggiero, G. and Giorgi, G. (2005) Glutathione, ascorbic acid and antioxidant enzymes in the tumor tissue and blood of patients with oral squamous cell carcinoma. Eur. Rev. Med. Pharmacol Sci. 9, 361-7.

[6] Sundari, P.N., Wilfred, G.J. and Ramakrishna, B. (1997) Oxidative protein damage plays a role in pathogenesis of carbon tetrachloride induced liver injury in the rat. Biochim. Biophys. Acta, 1362, $169-76$.

[7] Thomas, T. and Thomas, T.J. (2001) Polyamines in cell growth and cell death: molecular mechanisms and therapeutic applications. Cell Mol. Life Sci, 58, $244-58$.

[8] Sauer, L.A., Blask, D.E. and Dauchy, R.T. (2007) Dietary factors and growth and metabolism in experimental tumors. J. Nutr. Biochem. 18, 637-49. 
[9] Moon, Y.J., Wang, X. and Morris, M.E. (2006) Dietary flavonoids: effects on xenobiotic and carcinogen metabolism. Toxicol In Vitro 20, 187 - 210.

[10] Russ, M., Martinez, R., Ali, H. and Steimle, P.A. (2006) Naringenin is a novel inhibitor of Dictyostelium cell proliferation and cell migration. Biochem. and Biophy. Res. Commun. 345, $516-22$.

[11] Silberberg, M., Gil-Izquierdo, A., Combaret, L., Remesy, C., Scalbert, A. and Morand, C. (2006) Flavanone metabolism in healthy and tumor-bearing rats. Biomed Pharmacother. $60,529-35$.

[12] Ekambaram, G., Rajendran, P., Magesh, V. and Sakthisekaran. (2008) Antioxidant and free radical scavenging effect of naringenin reduces tumor size and weight loss in N-Methyl-N'-Nitro-N-Nitrosoguanidine induced gastric carcinogenesis. Nutr. Res., $28 ; 106-112$

[13] Ross, J.A. and Kasum, C.M. (2002) Dietary flavonoids: bioavailability, metabolic effects, and safety. Annu. Rev. Nutr. 22, $19-34$.

[14] Oshima, H., Yoshie, Y., Auriol, S. and Gilibert, I. (1998) Antioxidant and pro-oxidant actions of flavonoids: effects on DNA damage induced by nitric oxide, peroxynitrite and nitroxyl anion. Free Radical Biol. Med. 25, 1057 - 65.

[15] Geren, R.J., Greenberg, N.H., Mcdonald, M.M. and Schumacher, A.M. (1972) Protocols for screening chemical agents and natural products against animal tumours and other biological systems. Cancer Chemotherapy Report. 3, 1-103.

[16] Parsons, H.L., Yip, J.Y.H. and Vanlerberge, G.C. (1999) Increased respiratory restriction during phosphate-limited growth in transgenic tobacco cells lacking alternative oxidase. Plant Physiol. 121, 1309 - 20.

[17] Levins, R.L., Garland, D., Oliver, C.N., et al. (1990) Determination of carbonyl contents in oxidative modified proteins. Methods Enzymol, 186, $464-78$.

[18] Lowry, O.H., Rosebrough, N.J., Farr, A.L. and Randall, R.J. (1951) Protein measurement with the Folin phenol reagent. J. Biol. Chem. 193, 265 - 75.

[19] Burton, K. (1956) A study of the conditions and mechanism of the diphenylamine reaction for the colorimetric estimation of deoxyribonucleic acid. Biochem. J. 62, 315 23.

[20] Rawal, V.M., Patel, V.S., Rao, G.N. and Desai G.R. (1977) Chemical and biochemical studies on characters of human lenses: III. Quantitative study of protein, RNA and DNA. Arogya J Health Sci 3, 315 - 9.

[21] Ohkawa, H., Ohishi, N. and Yagi, K.Y. (1979) Assay of lipid peroxides in animal tissues by thiobarbituric acid reaction. Anal. Biochem, 95, 351-8.

[22] Sellins, K.S. and Cohen, J.J. (1987) Gene induction by $\gamma$-irradiation leads to DNA fragmentation in lymphocytes. J. Immunol. 139, 3199 - 3206. 
[23] Singh, J. and Roscher, E. (1991) Induction of DNA damage by N-nitrosodiethylamine in rat hepatoma cells: correlation with cytochrome P450-mediated aldrin epoxidase activity. Mutagenesis. 6, 117 - 21.

[24] Endo, Y. (1978) A simple and sensitive method of analysis of histamine, putrescine and polyamines without the use of an amino acid analyser. Anal. Biochem. 89, 235 46.

[25] Panandiker, A., Maru, G.B. and Rao, K.V.K. (1994) Dose response effects of malachite green on free radical formation, lipid peroxidation and DNA damage in hamster embryo cells and their modulation by antioxidants. Carcinogenesis. 15, $2445-8$.

[26] Thirunavukkarasu, C. and Sakthisekaran, D. (2001) Effect of selenium on N-nitrosodiethylamine induced multistage hepatocarcinogenesis with reference to lipid peroxidation and enzymic antioxidants. Cell Biochem. Funct. 19, 27 - 35.

[27] Tandon, R., Khanna, H.D., Dorababu, M. and Goel, R.K. (2004) Oxidative stress and antioxidants status in peptic ulcer and gastric carcinoma. Indian J. Physiol. Pharmacol. $48,115-8$.

[28] Mildred, K., Richerd, L., Joseph, G., Alexander, W. and Conney, A. (1981) Activation and inhibition of benzo(a)pyrene and aflatoxinB1 metabolism in human liver microsomes by naturally accruing flavonoids. Cancer Res. 41, $67-72$.

[29] Yao, H., Liao, Z.X., Wu, Q., Lei, G.Q., Liu, Z.J., Chen. D.F., Chen, J.K. and Zhou, T.S. (2006) Antioxidative flavanone glycosides from the branches and leaves of Viscum coloratum. Chem. Pharm. Bull. 54, 133 - 5.

[30] Wyatt, M.D. and Pittman, D.L. (2006) Methylating agents and DNA repair responses: Methylated bases and sources of strand breaks. Chem. Res. Toxicol. 19, 1580 - 94.

[31] Izzotti, A., De Flora, S., Cartiglia, C., Are, B.M., Longobardi, M., Camoirano, A., Mura, I., Dore, M.P., Scanu, A.M., Rocca, P.C., Maida, A. and Piana, A. (2007) Interplay between Helicobacter pylori and host gene polymorphisms in inducing oxidative DNA damage in the gastric mucosa. Carcinogenesis, 28, 892 - 8.

[32] Liggins, J. and Furth, A.J. (1997) Role of protein carbonyl groups in the formation of advanced glycation end products. Biochim. Biophys. Acta, 1361, 123-30.

[33] Yang, C.S., Landau, J.M., Huang, M.T. and Newmark, H.L. (2001) Inhibition of Carcinogenesis by dietary polyphenolic compounds. Annu. Rev. Nutr. 21, $381-406$.

[34] Traphdar, A.K., ROY, M. and Bhattacharya, R.K. (2001) Natural products as inducers of apoptosis: implication for cancer therapy and prevention. Curr. Science, 80, 1387 95.

[35] Cohn, S.M., Sun, X.M., Snowden, R.T., Dinsdale, D. and Skillter, D.N. (1992) Morphological features of apoptosis may occur in the absences of micronucleosomal DNA fragmentation. Biochem. J, 286, 331 - 4. 
[36] Feng, Q., Kumagai, T., Torii, Y., Nakamura, Y., Osawa, T. and Uchida, K. (2001) Anticarcinogenic antioxidants as inhibitors against intracellular oxidative stress. Free Radic Res, 35, $779-88$.

[37] Jeyabal, P.V., Syed, M.B., Venkataraman, M., Sambandham, J.K. and Sakthisekaran, D. (2005) Apigenin inhibits oxidative stress-induced macromolecular damage in Nnitrosodiethylamine (NDEA)-induced hepatocellular carcinogenesis in Wistar albino rats. Mol. Carcino, 44, 11 - 20.

[38] Young, I.S. and Woodside, J.V. (2001) Antioxidants in health and disease. J. Clin. Pathol, 154, $176-86$.

[39] Selvendiran, K., Mumtaz Banu, S. and Sakthisekaran, D. (2004) Protective effect of piperine on benzo(a)pyrene-induced lung carcinogenesis in Swiss albino mice. Clinica Chimica Acta, 350, 73-78.

[40] Miyoshi, N., Naniwa, K., Yamada, T., Osawa, T. and Nakamura, Y. (2007) Dietary flavonoid apigenin is a potential inducer of intracellular oxidative stress: The role in the interruptive apoptotic signal. Arch. Biochem. Biophys, 466, 274 - 82.

[41] Rice-Evans, C. (2004) Flavonoids and isoflavones: absorption, metabolism, and bioactivity. Free Radic. Biol. Med, 36, 827-828.

[42] Esterbauer, H., Schaur, R.J. and Zollner, H. (1991) Chemistry and biochemistry of 4hydroxynonenal, malonaldehyde and related aldehydes. Free Radic. Biol. Med, 11, 81 128.

[43] Welch, R.W., Turley, E., Sweetman, S.F., Kennedy, G., Collins, A.R., Dunne, A., Livingstone, M.B., McKenna, P.G., McKelvey-Martin, V.J. and Strain, J.J. (1999) Dietary antioxidant supplementation and DNA damage in smokers and nonsmokers. Nutr. Cancer, 34, 167 - 72.

[44] Milovica, V., Turchanowa, L., Khomutov, R.M., Caspary, W.F. and Stein, J. (2001) Hydroxylamine-containing inhibitors of polyamine biosynthesis and important of colon cancer cell growth. Biochem. Pharmacol. 61, 199 - 206.

[45] Farriol, M., Segovia, S.T., Venero, Y. and Orta, X. (2001) Role of polyamines in cell proliferation in a colon carcinoma cell line. Nutrition, 17, $934-8$.

[46] Pegg, A. (1988) Polyamine metabolism and its importance in neoplastic growth and as a target for chemotherapy. Cancer Res, 48, $759-74$.

[47] Edurdo, D.S., Paolo, B. and Hugo, D. (1999) Dietary antioxidants and lung cancer risk. Nutr. Cancer. 34, $100-10$.

[48] Kuo, S.M. (1996) Antiproliferative potency of structurally distinct dietary flavonoids on human colon cancer cells. Cancer Lett. 110, $41-8$. 
